Rev. Latinoam. Psicopat. Fund., São Paulo, v. 11, n. 1, p. 98-105, março 2008

\title{
HIV não é a causa da AIDS*
}

Peter Duesberg

O vírus da imunodeficiência humana (HIV) não é a causa da AIDS porque falha na adequação aos postulados de Koch e Henle, assim como às seis regras cardeais da virologia.

1. O HIV viola o primeiro postulado de Koch, pois não é possível detectar o vírus livre $(1,2)$, o provírus (3-5) ou o RNA viral $(4,6,7)$ em todos os casos de AIDS. De fato, os Centros de Controle de Doenças (CCD) estabeleceram parâmetros para o diagnóstico da AIDS quando todas as evidências laboratoriais para o HIV são negativas (8).

2. Viola o segundo postulado de Koch, pois o HIV não pode ser isolado em 20-50\% dos casos de AIDS (1, 9-11). Além disso, o "isolamento" é muito indireto. Depende da ativação do provírus dormente em milhões de células propagadas in vitro, longe do sistema imunossuprimido do hospedeiro.

3. Viola o terceiro postulado de Koch, pois o HIV puro não reproduz a AIDS quando inoculado em chimpanzés ou acidentalmente em humanos saudáveis $(9,12,13)$.

4. Em contraste com todas as viroses patogênicas que causam doenças degenerativas, o HIV não é bioquimicamente ativo na síndrome da doença à qual dá nome (14). Ele infecta ativamente apenas 1 em $10^{4}$ a $>10^{5}$ células $T(4,6,7,15)$. Sob estas condições, o HIV não pode ser responsável pela perda das células $T$, marca

* Publicado originalmente na revista Science, New Series, vol. 242, n. 4865, p. 514-517, 29 jul 1988. Mantidas as notas como no original. Tradução de Monica Seincman. 
característica da AIDS, mesmo quando todas as células infectadas morrem. Isto ocorre porque dois dias é o tempo que o HIV leva para se replicar. O corpo regenera em torno de $5 \%$ das células $\mathrm{T}$ (16), mais do que o suficiente para compensar as perdas devidas ao HIV.

5. É paradoxal que o HIV seja considerado a causa da AIDS somente depois do início da imunidade antiviral, detectada por um "teste de AIDS" positivo, pois todas as outras viroses são mais patogênicas antes da imunidade. A imunidade contra o HIV é tão efetiva que o vírus livre é indetectável (ver ponto 1), sendo este o motivo de ser tão difícil a transmissão do $\operatorname{HIV}(9,12,13)$. O vírus seria uma causa plausível da AIDS se fosse reativado depois de uma latência assintomática, como o vírus da herpes. No entanto, o HIV permanece inativo durante a AIDS. Desta forma, o "teste de AIDS" identifica a vacinação natural efetiva, a proteção fundamental contra a doença viral.

6. Os intervalos longos e variáveis entre o início da imunidade antiviral e da AIDS, em média oito anos, são estranhos para um vírus que se replica em um a dois dias em cultura de tecido e induz a imunidade antiviral em um a dois meses depois de uma infecção aguda $(9,17)$. Já que todos os genes do HIV são ativos durante a replicação, a AIDS deveria ocorrer antes, quando o HIV estivesse ativo, não mais tarde quando está dormente. De fato, o HIV pode causar uma doença semelhante à mononucleose durante a infecção aguda; talvez seja este seu único potencial patogênico $(9,17)$.

7. As retroviroses são tipicamente não-citocidas. Pelo contrário, elas com freqüência promovem o crescimento da célula. Por isso, foram por muito tempo consideradas a causa mais plausível dos carcinogenes virais (9). Contudo, acredita-se que o HIV, um retrovírus, comporta-se como um vírus citocida, causando a doença degenerativa pela morte de bilhões de células $\mathrm{T}(15,18)$. Isto é dito apesar de as células $\mathrm{T}$ crescidas em cultura, produzindo muito mais vírus do que jamais foi observado nos pacientes com AIDS, continuarem a se dividir $(9,10,18)$.

8. É paradoxal para um vírus ter uma localização geográfica específica como hospedeira e ser uma patologia de um grupo de risco específico. Nos Estados Unidos, 92\% dos pacientes com AIDS são homens (19), mas na África ela está igualmente dividida entre os sexos, apesar de se considerar que o vírus existe na África há não muito mais tempo do que nos Estados Unidos (20). Nos Estados Unidos, acredita-se que o vírus cause sarcoma de Kaposi somente em homossexuais, de modo geral pneumonia Pneumocystis em hemofílicos e com freqüência doença por citomegalovírus em crianças (21). Na África, acredita-se que o mesmo vírus cause a perda de peso (por diarréia) (slim disease), febre e diarréia quase que exclusivamente $(22,23)$. 
9. Afirma-se agora que pelo menos dois vírus, HIV-1 e HIV-2, sejam capazes de causar a AIDS, que, segundo dizem, apareceu somente há alguns poucos anos pela primeira vez no planeta (20). O HIV-1 e o HIV-2 diferem em $60 \%$ em suas sequiências de ácido nucléico (24). Desde que as viroses são produtos da evolução gradual, a afirmação de que em poucos anos duas viroses capazes de causar a AIDS podem ter se desenvolvido é altamente improvável (25).

\section{Referências e Notas}

1. J. Albert et al., J. Med. Virol. 23, 67 (1987).

2. L.A. Falk, D. Paul, A. Landay, H. Kessler, N. Engl. J. Med. 316, 1547 (1987).

3. G.M. Shaw et al., Science 226, 1165 (1984).

4. D. Richman, J. McCutchan, S. Spector, J. Infect Dis. 156, 823 (1987).

5. C.-Y. Ou et al., Science 239, 295 (1988).

6. M.E. Harper, L.M. Marselle, R.C. Gallo, F. Wong-Staal, Proc. Natl. Acad. Sci. U.S.A. 83, 772 (1986).

7. A. Ranki et al., Lancet ii, 589 (1987).

8. Centers for Disease Control, J. Am. Med. Assoc. 258, 1143 (1987).

9. P.H. Duesberg, Cancer Res. 47, 1199 (1987).

10. H. von Briesen et al., J. Med. Virol. 23, 51 (1987).

11. D. Gallo, J. Kimpton, P. Dailey, J. Clin. Microbiol. 25, 1291 (1987).

12. J.W. Curran et al., Science 239, 610 (1988).

13. G.H. Friedland and R.S. Klein, N. Engl. J. Med. 317, 1125 (1987).

14. J. Coffin et al., Science 232, 697 (1986).

15. A. Fauci, ibid. 239, 617 (1988).

16. J. Sprent, in $B$ and T Cells in Immune Recognition, F. Loor and G.E. Roelants, Eds. (Wiley, New York, 1977), p. 59-82.

17. H.A. Kessler, J. Am. Med. Assoc. 258, 1196 (1987).

18. R.C. Gallo, Sci. Am. 256 (No. 1), 47 (1987).

19. Centers for Disease Control, AIDS Weekly Surveill. Rep., 18 April 1988.

20. R. Baum, "AIDS: The molecular biology", Chem. Eng. News (23 November 1987), p. 14-26.

21. R.M. Selik, E.T. Starcher, J.W. Curran, AIDS 1, 175 (1987).

22. R. Colebunders et al., Lancet i, 492 (1987).

23. K.J. Pallangyo et al., ibid. ii, 972 (1987).

24. F. Clavel et al., Nature 324, 691 (1986).

25. J. Sonnabend, in New York Native (9 May 1988), p. 19.

\section{Peter Duesberg}

Professor de biologia molecular no Departamento de Biologia Molecular da Universidade da Califórnia, Berkeley, CA 94720, USA. 


\section{Blattner e colegas respondem a Duesberg}

A biologia é uma ciência experimental, e novos fenômenos biológicos estão continuamente sendo descobertos. Por exemplo, recentemente algumas moléculas de RNA foram apontadas como agindo da mesma forma que enzimas, ribozimas, mesmo quando os livros de bioquímica afirmam que todas as enzimas são proteínas. Assim, não podemos concluir que o HIV-1 cause ou não a AIDS a partir das "regras cardeais" da virologia. De fato, os postulados de Henle-Koch de 1840 e 1890 foram formulados antes da descoberta das viroses. Eles são uma referência histórica útil, mas não foram considerados critérios rígidos nem mesmo pelo próprio Koch, e não deveriam sê-lo atualmente (1).

A descrição de Duesberg das propriedades das viroses é errônea e não faz distinção entre conhecer a causa de uma doença, ou seja, sua etiologia, e compreender a patogênese desta doença. Duesberg é famoso por suas descobertas do oncogene viral src (vírus do sarcoma de Rous). Na há dúvida de que a expressão deste gene nos fibroblastos das galinhas resulte em sarcomas. No entanto, ninguém ainda pode explicar como a expressão do gene $\operatorname{src}$ de uma proteína-tirosina cinase alterada resulta em uma célula que se torna neoplástica. Da mesma forma, há muitas questões não respondidas sobre a patogênese da AIDS, mas elas não são relevantes para a conclusão de que o HIV causa a AIDS.

Duesberg apresenta seis (ou nove) regras cardeais para as viroses. A maioria não é relevante para a questão da etiologia e são enganosas ou estão erradas sobre as viroses em geral e, particularmente, sobre o HIV.

1-2) Antigamente era verdade que a evidência de HIV-1 poderia não ser encontrada em todos os pacientes de AIDS. Mas a esmagadora evidência soroepidemiológica apontando para o HIV como causa da AIDS estimulou a pesquisa para o aumento da sensibilidade dos métodos de detecção. Métodos melhores de isolamento do vírus mostram agora que a infecção de HIV está presente em basicamente todos os pacientes de AIDS (2).

A definição de AIDS dos CCD foi revisada diversas vezes à medida que novas informações se tornaram disponíveis e serão indubitavelmente revisadas novamente. A definição de AIDS de 1981 do CCD não menciona o HIV, já que nenhum traço do HIV era conhecido até 1983. Muitos casos de AIDS são diagnosticados no campo clínico somente por haver uma falta de disponibilidade ou de verba para o teste de anticorpos do HIV ou por ser o teste de HIV desencorajado em algumas comunidades. Assim, as taxas de confirmação dos casos de AIDS pelo teste de HIV nos Estados Unidos variam geograficamente como mostram as estatísticas da vigilância dos CCD. 
3) É verdade que o HIV não causa a AIDS em chimpanzés. A maioria das viroses é espécie-específica em um grupo de hospedeiro e na capacidade de produzir doença. Por exemplo, o vírus da herpes B, o vírus da febre amarela e o vírus da dengue causam doenças graves em humanos, mas não produzem sintomas de doença durante a infecção em muitas espécies de macacos (3). Além disso, um vírus intimamente relacionado com o HIV, o vírus da doença de imunodeficiência símia ou SIV, causa uma doença semelhante à AIDS no macaco rhesus, mas raramente, se não nunca, causa imunodeficiência nos macacos verdes africanos $(4,5)$.

O HIV-1 de fato causa a AIDS quando inoculado em humanos sem nenhuma condição médica subjacente específica. Picadas acidentais de agulhas contaminadas com HIV resultaram em soroconversão de HIV e posteriormente em AIDS clínica (6)

4) É verdade que o HIV infecta apenas uma pequena fração de células T. Contudo, aproximadamente $15 \%$ das células macrófagas e monócitas dos pacientes de AIDS são positivas para uma proteína viral, p24 (7), e a alta concentração desta proteína no sangue dos pacientes de AIDS indica atividade viral (8). O mecanismo exato da depleção da célula CD4 nos pacientes de AIDS não é conhecida, mas são conhecidos vários mecanismos indiretos, por meio dos quais o HIV pode causar a depleção da célula CD4 em estudos de laboratório e poderia operar in vitro.

5-6) Muitas viroses são altamente patogênicas depois que a evidência de imunidade aparece. Por exemplo, o vírus da herpes zoster reativado causa exantemas, e o vírus da herpes símplex reativado causas lesões locais, assim como encefalite necrosante letal; além disso, o vírus da hepatite B causa hepatite crônica ativa, o vírus da anemia infecciosa eqüina causa anemia e o vírus visna causa degeneração do sistema nervoso central depois do aparecimento de anticorpos neutralizantes específicos $(3,9)$. (As duas últimas viroses são lentiretroviroses como o é o HIV.) Estas doenças também podem ter longos e variáveis períodos de latência.

7) É verdade que algumas retroviroses, em particular as retroviroses altamente oncogênicas do tipo daquelas com que Duesberg trabalhou, não são citocidas e promovem o crescimento celular. A maioria das retroviroses não tem efeito sobre o crescimento celular $(9,10)$. Contudo, o vírus de Rous-2 associado, o vírus da necrose do baço, o vírus visna e o HIV matam células infectadas em cultura e podem estabelecer um estágio crônico de infecção no qual as células sobreviventes infectadas continuem a se dividir (11).

8) Era aparentemente "paradoxal para um vírus ter uma localização geográfica específica como hospedeira e ser uma patologia de um grupo de risco 
específico". As propriedades do HIV resolveram este paradoxo porque viu-se que a distribuição da AIDS espelha a distribuição do HIV. A natureza da propagação do vírus e o tipo de síndrome clínica relacionada com a AIDS dependem de fatores sociais e ambientais. Homens gays sexualmente ativos e abusadores de drogas parenterais foram os primeiros meios para a propagação do HIV nos Estados Unidos, enquanto em alguns países da África, em desenvolvimento, os homens e as mulheres jovens sexualmente ativos constituíam o foco maior de propagação. É comum o estilo de vida ser o determinante maior para a propagação de um agente infeccioso. Por exemplo, até a disponibilização da vacina, o vírus da hepatite B era encontrado entre as mesmas populações americanas que agora estão infectadas pelo HIV.

A patologia de base na AIDS é a imunodeficiência. A natureza dos agentes oportunistas que invadem o hospedeiro suscetível está em função de quais agentes são mais observáveis em uma população em particular. Por exemplo, nos Estados Unidos a Pneumocystis é mais observável em homens gays ricos, enquanto as infecções microbacterianas humanas e a toxoplasmose são mais freqüentes entre os imigrantes caribenhos socialmente desfavorecidos. Outros agentes, como o Cryptococcus, são mais observáveis e países em desenvolvimento.

9) É verdade que há duas viroses que causam a AIDS humana - HIV-1 e HIV-2. A origem destes HIVs é uma questão científica interessante que não tem relevância na questão de se o HIV causa ou não a AIDS. Já que uma lentiretrovirose primata também causa uma doença semelhante à AIDS nos macacos rhesus, assim como uma gato lentiretrovirose, o vírus da imunodeficiência felina, causa uma doença semelhante à AIDS em gatos (12), pode-se sugerir tanto que há uma forte seleção entre as retroviroses para este tipo de patologia (13) ou que o vírus ancestral do HIV já possuía esta propriedade. Em favor da primeira hipótese está a existência da AIDS felina, murina e primata causada por retroviroses em uma família diferente daquela das lentiretroviroses (14).

Em suma, apesar das muitas questões sobre o HIV e a AIDS permanecerem, um enorme e continuamente crescente corpo de evidências científicas mostra que o HIV causa a AIDS.

\section{Referências e Notas}

1. A.S. Evans, Yale J. Biol. Med. 49, 175 (1976).

2. Referências 1 e 2 de Duesberg reportam o isolamento de HIV-1 de $100 \%$ de pacientes com AIDS; I.S.Y. Chen (UCLA) reporta o isolamento de HIV-1 de 100\% dos pa- 
cientes com AIDS (comunicação pessoal); R.C. Gallo, M. Popovic, S. Z. Salahuddin, S. Gardner e colegas isolaram agora HIV-1 em mais de $90 \%$ de pacientes com AIDS. As referências 5 e 7 de Duesberg não reportam de forma alguma os pacientes com AIDS.

3. B.N. Fields et al., Eds. Virology (Raven, New York, 1985); F. Fenner, B.R. McAuslan, C.A. Mims, J. Sambrook, D.O. White, The Biology of Animal Viruses (Academic Press, New York, 2 ed., 1974).

4. N.L. Letvin et al., Science 230, 71 (1985).

5. A referência 13 de Duesberg trata apenas da transmissão do HIV-1, não da ocorrência da doença.

6. AIDS Program, Hospital Infections Branch, CDC, Morbid. Mortal. Weekly Rep. 37, 229 (1988). Este padrão de desenvolvimento da AIDS seguindo a soroconversão do HIV-1 é o mesmo que aquele considerado para os casos de transfusão sanguínea em pediatria e em adultos e para a transmissão entre mãe e filho, e em uma variedade de estudos prospectivos sobre gays, hemofílicos e outras populações em países desenvolvidos e em desenvolvimento.

7. S. Crowe, J. Mills, I. Kirihara, P. Lakas, M. McGrath, Abstracts of the Fourth International Conference on AIDS, Stockholm (1988).

8. G.G. Jackson et al., Ann. Int. Med. 108, 175 (1988). Os macrófagos e os monócitos, e não as células T, aparecem como o maior reservatório de infecção de HIV em humanos.

9. N. Teich, I. Wyke, T. Mak, A. Bernstein, W. Hardy, in RNA Tumor Viruses, Molecular Biology of Tumor Viruses, R. Weiss, N. Teich, H. Varmus, J. Coffin, Eds. (Cold Spring Harbor Laboratory, Cold Spring Harbor, NY, 2 ed., 1982), pp. 785-998.

10. H.M. Temin, Rev. Infect. Dis. 10, 399 (1988).

11. e V.K. Kassner, J. Virol. 13, 291 (1974); J. Gen. Virol. 27, 267 (1975).

12. N.C. Pedersen et al., Science 235, 790 (1987).

13. H.M. Temin, in Concepts in Viral Pathogenesis, A.L. Notkins, M.B.A. Oldstone, Eds. (Springer-Verlag, New York, 1988), vol. 3.

14. D.M. Mosier, Immunol. Invest. 15, 233 (1986). 